\title{
Structures, Targets and Recent Approaches in Anti-Leishmanial Drug Discovery and Development
}

\author{
Karin Seifert*
}

London School of Hygiene \& Tropical Medicine, Keppel Street, London WC1E 7HT, UK

\begin{abstract}
Recent years have seen a significant improvement in available treatment options for leishmaniasis. Two new drugs, miltefosine and paromomycin, have been registered for the treatment of visceral leishmaniasis (VL) in India since 2002. Combination therapy is now explored in clinical trials as a new treatment approach for VL to reduce the length of treatment and potentially prevent selection of resistant parasites. However there is still a need for new drugs due to safety, resistance, stability and cost issues with existing therapies. The search for topical treatments for cutaneous leishmaniasis (CL) is ongoing. This review gives a brief overview of recent developments and approaches in anti-leishmanial drug discovery and development.
\end{abstract}

Keywords: Leishmaniasis, drug discovery, drug development.

\section{LEISHMANIASIS}

Leishmaniasis is a disease complex caused by protozoan parasites of the genus Leishmania. Parasites are transmitted by female sandflies via anthroponotic or zoonotic cycles [1]. Leishmania parasites have a dimorphic life-cycle; promastigotes develop in the gut of female sandflies to infectious forms that are transmitted to mammalian hosts [2,3]. Inside the host parasites survive and multiply as amastigotes within parasitophorous vacuoles (PVs) of macrophages [4,5]. Main clinical manifestations include visceral leishmaniasis (VL) and cutaneous leishmaniasis (CL) and rarer manifestations such as mucosal leishmaniasis and post-kala-azar dermal leishmaniasis (PKDL). An estimated 350 million people are at risk of infection and disease worldwide. The annual incidence is estimated at $1.5-2$ million with 70000 deaths each year [1]. However due to underreporting and misdiagnosis actual case loads are expected to be higher. Leishmaniasis is included in the neglected tropical diseases (NTDs) [6] and a strong link to poverty is recognized [7]. Epidemiology, pathogenesis, diagnosis and disease control have recently been reviewed $[1,8]$.

\section{DRUGS AVAILABLE AND IN CLINICAL TRIALS}

The following paragraphs provide an overview of currently used and clinically investigated anti-leishmanial drugs. Consideration is given to clinical data, reported toxicities and pharmacokinetics (PKs), chemistry, their mode of action (MOA) and cellular targets.

\section{Pentavalent Antimonials}

Pentavalent antimonials (meglumine antimonate (MA) and sodium stibogluconate (SSG)) have been used in the

\footnotetext{
*Address correspondence to this author at the London School of Hygiene \& Tropical Medicine, Keppel Street, London WC1E 7HT, UK;

Tel: +44 (0)207 927 2643; Fax: +44 (0)207 927 2807;

E-mail: Karin.Seifert@1shtm.ac.uk
}

treatment of VL and CL for more than 60 years. Response rates are still over $95 \%$ in previously untreated VL patients in many parts of the world, but acquired resistance to pentavalent antimony $\left(\mathrm{Sb}^{\mathrm{v}}\right)$ has developed in the highprevalence, high-transmission epidemic region of Bihar, India [9]. Failure rates of $65 \%$ have been reported and the use of antimony abandoned in this region [10]. Other issues related to treatment include confirmation of drug efficacy, side effects of low-cost generic drugs and lot-to-lot variation [11]. Cardiotoxicity has been reported as drug-induced effect $[12,13]$. Serious cardiotoxicity is seen in $9-10 \%$ of treated patients. Higher rates have been reported due to improper formulation of drug and use of lots with high osmolarity [13]. Pharmacokinetics of pentavalent antimonials has been described by a two compartment, three term pharmacokinetic model. An initial absorbtion phase was followed by a rapid elimination phase (mean half-life 2.02h) and a slow elimination phase (mean half-life 76 hours) in patients treated with MA or SSG [14]. In infected dogs treated with multiple doses of MA an absorption phase was followed by a rapid disposition phase (half-life $\alpha 1.41$ hours) and a slower terminal phase (half-life $\beta 8.76$ hours) [15].

The chemical structure and composition of meglumine antimonate and sodium stibogluconate have recently been reevaluated by electrospray ionization mass spectrometry (ESI-MS) and osmolarity measurements [16]. The authors reported that MA and SSG consist as mixtures of 2:2, 2:3 and 2:1 Sb${ }^{\mathrm{v}}$-ligand complexes in concentrated aqueous solutions. Increasing depolymerisation occurs with increasing dilution and conversion of the highly aggregated state into dissociated complexes and antimonate is expected in human serum after drug administration. 1:1 $\mathrm{Sb}^{\mathrm{v}}$-ligand complexes, together with antimonate, are expected to be the final $\mathrm{Sb}^{\mathrm{v}}$ form of these drugs and pharmacologically relevant [16].

Pentavalent antimonials are now generally accepted as prodrugs which require reduction to the trivalent form for 
biological activity. The site of reduction (macrophage, amastigote or both) and the mechanism (enzymatic or nonenzymatic) remain unclear. Early studies have implicated inhibition of energy metabolism and macromolecular biosynthesis via inhibition of glycolysis and fatty acid betaoxidation in the mechanism of action of sodium stibogluconate $[17,18]$. Specific targets in these pathways have not been identified. Trivalent antimony has recently been shown to directly interfere with thiol metabolism in drug-sensitive L. donovani with several effects on glutathione and trypanothione metabolism [19].

\section{Amphotericin B}

Amphotericin B is a polyene antibiotic, which was originally extracted from Streptomyces nodosus. Crystalline amphotericin B is insoluble in water and different formulations are available. Amphotericin B deoxycholate (Fungizone $\left.{ }^{\circledR}\right)$, a micellar formulation, is highly effective. It is used as first line treatment in areas with high rates of unresponsiveness to antimonials and second line treatment elsewhere [11]. Lipid based formulations of amphotericin B are available and liposomal amphotericin B (AmBisome $\left.{ }^{\circledR}\right)$ has been approved for treatment of VL by the U.S. Food and Drug Administration (FDA) [20]. Shorter treatment courses and single dose regimes of liposomal amphotericin $\mathrm{B}$ have been investigated in the state of Bihar, India [21-23]. The most recent study tested the efficacy of liposomal amphotericin B at a single dose of $10 \mathrm{mg} / \mathrm{kg}$ in comparison to 15 alternate-day infusions of amphotericin B deoxycholate at a dose of $1 \mathrm{mg} / \mathrm{kg}$. Single dose liposomal amphotericin B was not inferior to and less expensive than amphotericin B deoxycholate, but a non-significantly higher relapse rate was noted in the liposomal treatment group [24]. Other commercially available lipid formulations, amphotericin B lipid complex (ABLC) and amphotericin B colloidal dispersion (ABCD) have also been tested for treatment of VL [25]. A commercially standardized product of amphotericin B deoxycholate premixed with lipid emulsion containing egg lecithin and soyabean oil (ABLE) is licensed in India for the use of VL. However overall cure rates in phase II clinical trials in India using this formulation as monotherapy were lower than the desired cure rate of approximately 95\% [26,27].

Need for hospitalization, constant monitoring of patients, prolonged duration of treatment and infusion-related adverse events (fever, chills, trombophlebitis) are drawbacks of amphotericin B deoxycholate. Toxicities such as hypokalaemia, nephrotoxicity and myocarditis can occur [12]. Liposomal amphotericin B is much safer than amphotericin B deoxycholate and also highly efficacious [11,12]. However high cost limits widespread use in many VL-endemic regions. Recently new preferential pricing was agreed for certain countries with a cost of $\$ 20$ per $50 \mathrm{mg}$ vial of AmBisome ${ }^{\circledR}$ [28]. In liposomal amphotericin B drug is formulated with cholesterol and other phospholipids within a small unilamellar liposome. Temperatures of $>25^{\circ} \mathrm{C}$ and $<0^{\circ} \mathrm{C}$ can alter liposome characteristics and may impact on efficacy and toxicity of liposomal amphotericin B [29]. ABLE is stable at higher temperatures for a certain time.

Characteristics that increase efficacy and minimize toxicity of liposomal amphotericin B are effective tissue penetra- tion with sustained levels and stability in blood, macrophages and tissues [29]. Tissue penetration is highest in liver and spleen. Preclinical pharmacokinetics of AmBisome ${ }^{\circledR}$ has been studied in mice, rats, rabbits and dogs. Its mean elimination half-life ranges from 5-24 hours depending on dose and species [30]. In humans the terminal elimination half-life after repeated administration of liposomal amphotericin B has been reported with around 7 hours [31]. Longer half-lifes have been reported with increased sampling times, but reported data in Leishmaniasis patients is limited. A study on L. infantum infected mice treated with multiple doses of AmBisome ${ }^{\circledR}$ also found high levels of the drug in liver and spleen [32].

Selectivity of amphotericin B against Leishmania is due to higher affinity of amphotericin B for 24-substituted sterols, the predominant sterol in Leishmania membranes, over cholesterol, the predominant sterol in mammalian cells. Interaction with membranes leads to formation of transmembrane amphotericin B channels, aqueous pores, and leakage of cations [33,34]. Selectivity and toxicity is also linked to the aggregation state of amphotericin B [34].

\section{Miltefosine}

Miltefosine is an alkylphosphocholine, originally developed as anti-cancer drug. It was the first oral anti-leishmanial drug that reached the market and is registered for treatment of VL in India and Germany and for CL in Colombia. It is used as potential tool in the elimination programme in India, Bangladesh and Nepal and as second line treatment for CL in Colombia and Bolivia [11].

General safety findings indicate the gastrointestinal tract as main target organ of side-effects [35]. Gastrointestinal symptoms were also recognized as the most common adverse effect in clinical trials [36]. Transient moderate elevation of hepatic enzymes was also observed. In a recent phase 4 study and in previous trials adverse events occurred more frequently in the first week of treatment and decreased with time [36]. The major limitation of miltefosine is its contraindication in pregnancy and mandatory contraception for women in child-bearing age for the duration of therapy and 2-3 months beyond. This restriction is based on a teratogenic effect seen in one species (rat) in preclinical studies [35] and the pharmacokinetic profile of miltefosine.

A recent study described the pharmacokinetics of miltefosine by a two-compartment disposition model with a first elimination half life of 7.05 days and a terminal half-life of 30.9 days in CL patients after treatment with $50 \mathrm{mg}$ miltefosine three times daily for a total of 28 days [37]. A long terminal half-life of 150 - 200 hours has previously been reported and concerns were raised that subtherapeutic levels of miltefosine in the body after completion of treatment might contribute to the emergence of resistance [38]. In the laboratory Leishmania promastigotes resistant to miltefosine concentrations of up to $40 \mu \mathrm{M}$ were easily generated and resistance was conferred to the intracellular amastigote stage $[39,40]$.

Uptake of miltefosine into L. donovani is mediated by a plasma membrane P-type ATPase aminophospholipid translocase [41-43]. Suggested targets of miltefosine in Leishma- 
nia include perturbation of ether-lipid metabolism, glycosylphosphatidylinositol (GPI) anchor biosynthesis and signal transduction [44] as well as inhibition of the glycosomal located alkyl-specific acyl-Co-A acyltransferase, an enzyme involved in lipid -remodeling [45]. Recently mitochondria and specifically the cytochrome $c$ oxidase have been implicated as target of miltefosine in L. donovani promastigotes [46]. Effects on lipid metabolism, specifically phospholipid content, fatty acid and sterol content, have also been described in L. donovani promastigotes [47].

\section{Paromomycin}

Paromomycin, an aminoglycoside antibiotic, is the latest anti-leishmanial drug registered for VL in India. In a randomized, controlled, phase 3 study in India paromomycin was shown to be noninferior to amphotericin B with a final cure rate of $94.6 \%$ versus $98.8 \%$ [48]. A recent study compared $11 \mathrm{mg} / \mathrm{kg} /$ day of paromomycin for 14 days to $11 \mathrm{mg} / \mathrm{kg} /$ day of paromomycin for 21 days in Indian VL. The definite cure rate in the short-course treatment group of 14 days was significantly lower than the rate in the 21 day treatment group ( $82 \%$ versus $92 \%$ based on intention-to-treat analysis) [49].

Paromomycin has also been formulated for topical treatment of CL $[11,50]$. It is used as topical treatment for CL in Israel in a methylbenzethonium chloride ointment (Leshcutan) [50]. Recently a phase 2 , placebo controlled study, carried out in Tunisia and France, reported efficacy (cure rate $94 \%$ ) and safety of the third generation aminoglycoside ointment WR279,396, a hydrophilic formulation of $15 \%$ paromomycin plus $0.5 \%$ gentamicin [51]. Local treatment of $\mathrm{CL}$ in the form of topical formulations offer the advantage of ease of administration, fewer side effects and costeffectiveness in comparison to systemic treatment [52].

Injection-site pain was the most frequently reported adverse event in the phase 3 trial for VL in India [48]. Ototoxicity and nephrotoxicity are known drug class effects, but frequency of these reactions has been reported as low at therapeutic dosages for VL [50]. Ototoxicity in a small percentage of patients in the recent phase 3 trial was reported as transient and reversible and the drug had a reasonable safety profile [48]. Monitoring of hepatic enzyme levels was recommended in the recent short-course trial [49].

Pharmacokinetic data has been reported from VL patients during the phase 3 trial. Paromomycin was absorbed quickly after intramuscular injection. Peak plasma levels were reached within 1 hour. Plasma levels 1 hour after injection ranged from $18.3 \mu \mathrm{g} / \mathrm{ml}$ to $20.5 \mu \mathrm{g} / \mathrm{ml}$ and trough plasma levels at 24 hours after injection from $1.31 \mu \mathrm{g} / \mathrm{ml}$ to 4.53 $\mu \mathrm{g} / \mathrm{ml}$. Plasma levels on days $1,8,15,21$ and 22 were similar [48]. Population estimates for absorbtion and elimination half-lives have been reported as 0.33 hours and 2.62 hours [50]. Pharmacokinetic data following a single intramuscular dose of paromomycin in healthy adult volunteers has also been reported [53].

Previous studies on paromomycin in Leishmania spp. have implicated mitochondrial membrane de-polarisation, ribosomes and respiratory dysfunction in the mode of action of this molecule [54-56]. Decreased drug uptake was shown in a paromomycin resistant L. donovani line [57]. Some of these findings have been confirmed in a recent study on $L$. donovani promastigotes [58].

\section{Pentamidine}

Pentamidine is an aromatic diamidine, still in use as first line drug for certain forms of CL. In VL it is used as secondline treatment only due to toxicity and efficacy issues [11]. The major safety concern with pentamidine is induction of insulin-dependent diabetes mellitus and in India its use for VL has been abandoned [12].

Early work has implicated the mitochondrion in the mode of action of pentamidine. Morphological changes with swelling of mitochondria and fragmentation of kinetoplastid DNA were reported in electron microscopy studies on Leishmania spp [59,60]. An uncoupling effect on mitochondria in situ with collapse of mitochondrial membrane potential was shown in L. donovani promastigotes [61]. Alkalisation of acidocalcisomes of $L$. donovani promastigotes has also been reported [62]. In a recent study mitochondria have been suggested as site of pentamidine accumulation in $L$. donovani and drug resistance associated with mitochondria alterations [63]. Pentamidine enters promastigotes and amastigotes of Leishmania via a carrier mediated process which recognizes diamidines with high affinity [64].

\section{Sitamaquine}

Sitamaquine (WR6026) is an 8-aminoquinoline currently in clinical development by Glaxo Smith Kline for oral treatment of VL [65]. Discovery of sitamaquine as antileishmanial agent was based on extensive efforts in synthetic chemistry at the Walter Reed Army Institute for Research (WRAIR) [66]. Recently results were reported from phase II dose ranging studies in India and Kenya. The overall cure rate at day 180 in the intention-to-treat-population was $83 \%$ in Kenyan patients [67] and $87 \%$ in Indian patients [68]. Abdominal pain and headache were reported in the Kenyan study and vomiting, dyspepsia and cyanosis by the Indian investigators. Methemoglobinemia is associated with 8aminoquinolines, but was only reported in Indian patients [68].

Studies using rat and hamster liver microsomes have identified two major metabolites of sitamaquine, the desethyl and $4-\mathrm{CH}_{2} \mathrm{OH}$ derivatives, with evidence of cytochrome P450 mediation $[65,69]$. Side chain oxidation and 5hydroxylation have been identified as important steps in the metabolic pathway of 8-aminoquinolines [65,70]. Presystemic eliminiation of sitamaquine in the liver with low systemic availability was observed in Beagle dogs [71]. The elimination half-life of sitamaquine in humans is reported as 26.1 hours. The major urinary metabolite in humans is the 4$\mathrm{CH}_{2} \mathrm{OH}$ derivative with a reported elimination half-life of 29.1 hours. A minor metabolite in humans is the desethyl species [65]. Metabolites may be linked to efficacy and toxicity of this compound.

Sitamaquine induced morphological changes in intracellular L. tropica amastigotes and host macrophages [59]. Collapse of mitochondrial membrane potential in $L$. donovani promastigotes has also been shown [61] as well as alkalisa- 
tion of acidocalcisomes [62]. Recently anti-leishmanial activity has been demonstrated as unrelated to sitamaquine accumulation in this organelle [72]. The interaction of sitamaquine with membrane lipids of $L$. donovani promastigotes has been assessed and described as a two-step process [73].

Chemotherapy and its role in treatment and control of leishmaniasis has recently been reviewed [11]. Treatment regimes of first and second line drugs against VL and CL and route of administration have been described [11,74].

\section{RECENT DEVELOPMENTS AND SELECTED DRUG CLASSES - FROM DISCOVERY TO PRECLINICAL STAGES}

The following paragraphs describe some new developments at the discovery and development stage. These include new compounds and new formulations of compounds and drugs for which in vivo efficacy has been demonstrated in relevant animal studies.

\section{2-Substituted Quinolines}

2-substituted quinoline alkaloids were originally isolated from a Bolivian medicinal plant (Galipea longiflora $\mathrm{Kr}, \mathrm{Ru}-$ taceae) and shown to have an effect in the treatment of experimental New World CL [75]. Activity of 2-substituted quinoline alkaloids was subsequently reported in the $L$. donovani - BALB/c mouse model with 2-n-propylquinoline showing significant activity after oral administration and chimanine D after subcutaneous administration [76]. Recent structure activity relationship (SAR) studies on a series of 2substituted quinolines concluded that the most active quinolines against intra-macrophage $L$. infanutm and L. amazonensis amastigotes in vitro had a three carbon alkenyl side chain with reactive electrophilic functions such as carbonyl, hydroxyl or halogen [77]. Significant efficacy of selected compounds was demonstrated in L. amazonensis and $L$. donovani infected BALB/c mice after oral administration. One compound emerged as the single compound with satisfactory activity across the in vivo models employed, containing a propenyl chain functionalized by an -OH group [78]. Biotransformation of this and other 2-substituted quinolines and their in vitro behavior in the blood compartment was studied showing discrepancies of affinity to erythrocytes amongst this series [79,80].

\section{8-Aminoquinolines}

8-aminoquinolines were originally developed as antimalarials, but have also shown promise in the treatment of leishmaniasis as seen with sitamaquine (WR6026, lepidine). Another 8-aminoquinoline, NPC1161, has shown activity against $L$. donovani in vivo in a similar order of magnitude to sitamaquine when tested as (-) enantiomer. Clear stereoselective differences in drug activity and toxicity were shown for this compound when tested as racemat, (-) or (+) enantiomer in the same study [81]. Synthesis and in vitro activities of other 8-aminoquinolines against $L$. donovani promastigotes have been reported $[82,83]$. These include derivatives with a 5-(3-trifluoromethylphenoxy) substitution on the quinoline ring and methyl-substituted, ethyl-substituted or unsubstituted C4 positions [82]. Notably the 5-(3-trifluoromethyl- phenoxy) substitution is also part of tafenoquine, another 8aminoquinoline with anti-parasitic activity [66].

\section{Buparvaquone and Derivatives}

Buparvaquone is a hydroxynaphtoquinone, which is currently marketed as Butalex ${ }^{\circledR}$ for the treatment of theileriosis in cattle. It was demonstrated as being highly active in vitro against intracellular $L$. donovani amastigotes in macrophages, but less active in vivo in the BALB/c mouse [84]. Its potent in vitro activity was recently confirmed against a range of Leishmania spp. with $\mathrm{EC}_{50}$ values for the intracellular amastigote stage in the low micromolar to nanomolar range [85]. The same study investigated water soluble phosphate prodrugs of buparvaquone and reported potent in vitro activity against CL and VL causing Leishmania species [85]. Buparvaquone oxime derivatives were also investigated, but displayed lower in vitro activity against $L$. donovani than the parent compound [86]. The prodrug approach is an effective way of improving oral bioavailability of poorly soluble drugs by chemical derivatization to more water soluble compounds. It is also used to improve topical drug delivery. Formulations for topical delivery of buparvaquone and a prodrug (3-phosphono-oxymethyl-buparvaquone) have been developed and characterized in in vitro human and mouse skin models [87]. Efficacy of topical formulations and phosphate prodrugs of buparvaquone in in vivo models of VL and CL has been reported [88].

\section{New Amphotericin B Formulations}

Recently a number of new amphotericin B formulations with high anti-leishmanial activity in vivo have emerged. The main focus of the re-formulation of this highly active molecule is to increase solubility and thermal stability and decrease systemic toxicity of amphotericin B. A reduced cost of new amphotericin B formulations is also desired. Solid nanoparticles of amphotericin B deoxycholate have shown activity after intraperitoneal injection into $L$. donovani infected hamsters with $99 \%$ suppression of parasite replication in the spleen at a dose of $5 \mathrm{mg} / \mathrm{kg} /$ day given for 5 days [89]. A novel lipid based amphotericin B formulation has recently been reported as active after oral administration in L. donovani infected mice. Parasitemia in the liver was inhibited by $99.5 \%$ and $99.8 \%$ at doses of 10 and $20 \mathrm{mg} / \mathrm{kg}$ twice daily for 5 days [90]. N-(2-hydroxypropyl)-methacrylamideGFLG-amphotericin B copolymer conjugates inhibited parasitemia by up to $94 \%$ in the liver of $L$. donovani infected $\mathrm{BALB} / \mathrm{c}$ mice after intravenous administration of $1 \mathrm{mg} / \mathrm{kg}$ amphotericin B equivalent on 3 alternate days and by up to $99.6 \%$ at a dose of $3 \mathrm{mg} / \mathrm{kg}$ amphotericin B equivalent [91]. This approach was extended to investigate poly(HPMA)GFLG-amphotericin B-alendronic acid conjugates as potential combination therapeutics in models of VL [92].

\section{RECENT DEVELOPMENTS - CLINICAL AND USE OF ANTI-LEISHMANIAL DRUGS}

The following paragraph describes new developments in the use of anti-leishmanial drugs available to patients. These include new treatment regimes in the form of combination chemotherapy or co-administration of drugs. 


\section{Combination Chemotherapy}

Advances in anti-leishmanial chemotherapy including the development of new drugs have made combination chemotherapy a real possibility. Multi-drug therapy is already standard practice in the treatment of other infectious diseases such as tuberculosis, leprosy and malaria [93-96]. Drug combinations aim to delay or prevent the emergence of resistance, shorten the course of treatment and lower required doses. Other potential advances include convenience, better compliance and lower costs [97]. A combination regime of sodium stibogluconate and paromomycin is currently employed in Sudan by Médecins sans frontiers (MSF) [98]. Single dose liposomal amphotericin B forms part of a new treatment approach for VL. A single dose of liposomal amphotericin B was followed by a short-course treatment of miltefosine for 7 - 14 days in a recent study in India. Results were satisfactorily with cure rates $>95 \%$ in the different treatment groups [97]. Further trials that investigate single dose liposomal amphotericin B followed by short treatment courses of miltefosine or paromomycin and the combination of miltefosine and paromomycin are completed, as is a trial investigating the combination of sodium stibogluconate and paromomycin (http://clinicaltrials.gov, accessed March $28^{\text {th }}$ 2010).

\section{DRUG TARGETS IN LEISHMANIA AND CHEMICAL STRUCTURES}

The following paragraphs describe potential drug targets in Leishmania with classes of chemical inhibitors where applicable and chemical structures for which a target has been demonstrated or a hypothesized target was starting point of the studies.

\section{Drug Targets}

Protein kinases are key regulatory proteins and represent a drug target in Leishmania and other trypanosomatids. Mitogen-activated protein kinases (MAP kinases), LmxMPK1 (Leishmania mexicana mitogen-activated protein kinase 1) and LmxMPK2 have been found essential for survival of amastigotes in infected hosts or the establishment of infections in mice [99]. Cyclin-dependent kinases have been chemically validated as potential drug targets by systematic analysis of chemical inhibitors. Thus L. mexicana CRK3 was screened against a chemical library of potential inhibitors and potent CRK3 inhibitors screened against intracellular $L$. donovani amastigotes in vitro. The most potent inhibitors were found to belong to the indirubin class of chemicals, others were 2, 6, 9-trisubstituted purines, paullones and derivatives of the non-specific kinase inhibitor staurosporine [100]. Recently 6-bromo substituted indirubins were reported as highly active in vitro against $L$. donovani and their action linked to CRK3 and GSK-3, a serine/threonine kinase [101]. Essentiality of protein kinases for proliferation and/or viability of the parasite and significant sequence differences from mammalian homologues are important points. The role of protein kinases as drug targets has been reviewed [102]. Currently the kinome of Leishmania is investigated in antileishmanial drug discovery [103].

Proteases (peptidases) are also explored and characterized as potential drug target in Leishmania [104,105].

\section{Chemical Structures}

Pentamidine analogues and aromatic diamidines are still of interest in anti-leishmanial integrating drug screens. Structure activity relationships (SAR) of synthetic compounds have recently been reported [106,107]. Binding of diamidines to DNA has been described and characterized [108].

Azasteroles are nitrogen containing sterol compounds. Azasterols with a nitrogen in the side chain of sterols at the 23-, 24-, or 25-position can inhibit the enzyme delta24-sterol methyltransferase (24-SMT) in fungi and plants and inhibit sterol biosynthesis [109]. A series of azasterols with and without protection at the $\mathrm{C}-3$ of the sterol nucleus has been assessed, but multiple modes of action were found against Leishmania spp. In vitro acitivity of C-3 protected azasterols was reported against intracellular $L$. donovani amastigotes [109]. In vitro activity was also reported for transition state analogues of 24-SMT [110]. A recent SAR study by the same group on new series of azasterols provided further insights into the pharmacophore of these compounds against $L$. donovani [111]. Their mode of action remains unclear.

Quinuclidine derivatives have shown in vitro activity against L. donovani axenic amastigotes. They act as leishmanial squalene synthetase inhibitors disrupting endogenous sterol biosynthesis [112].

\section{APPROACHES AND STRATEGIES IN ANTI- LEISHMANIAL DRUG DISCOVERY AND DEVEL- OPMENT}

Different approaches are used in drug discovery with molecular-target based approaches and exploratory drug screening at both ends of the spectrum. Molecular approaches, whole cell based approaches and a compromise approach between the two have their own values in antiparasitic drug discovery [113-115]. Criteria for target assessment and different target validation methods have recently been described [113]. An open access database for tropical diseases has been established to merge data from genome sequencing and functional genomics projects, protein structural data and provide information on target essentiality and druggability $[115,116]$.

The development process is guided by target product profiles (TPP), a list of key attributes for potential new drugs [113,117]. For leishmaniasis these attributes entail activity against VL and CL, short treatment courses, injectable agent with reduced treatment time, the desire for an oral drug, an improved safety profile, costs less than current treatment, stability under tropical conditions, the desire for a topical application for CL and the potential to combine with exisiting agents [117]. Definitions for "hit" and "lead" along with hit-to-lead identification criteria and lead optimization and candidate selection criteria have been summarized. These can be used complementary to the TPP in decision making on further progression of compounds in the development process [118].

A number of new public-private partnerships, non-profit organizations and consortia have been established in recent years to increase support of drug discovery and development for neglected and parasitic or tropical diseases. These include 
the Drugs for Neglected Diseases Initiative (DNDi) and The Consortium for Parasitic Drug Development (CPDD). Philanthropic organizations (including the Bill and Melinda Gates Foundation) and governments are also lending increased (financial) support [114-119]. Long standing programmes such as the TDR Screening Network are continued and have evolved to address the need of different stages and aspects in the drug discovery and development process. These include target selection, medicinal chemistry and drug metabolism and pharmacokinetics (DMPK) [117,118]. The integration of these aspects and new technologies, either within an initiative or as networks of partners with complementary expertise is important to sustain and feed the development pipeline.

\section{CONCLUSION}

In recent years advances have been made in the treatment of leishmaniasis. New drugs and treatment regimes are available or on the way to availability. The approach to drug discovery and development has also changed and advanced to include and integrate aspects as outlined above. The need to search for better, safer and simpler treatments continues.

\section{ACKNOWLEDGEMENTS}

The author thanks Prof. Simon Croft and Dr. Philippe Loiseau for reading of the manuscript. The author is funded by the European Community (FP7).

\section{REFERENCES}

[1] Reithinger, R.; Dujardin, J. C.; Louzir, H.; Pirmez, C.; Alexander, B.; Brooker, S. Cutaneous leishmaniasis. Lancet Infect. Dis., 2007, 7, 581-96.

[2] Bates, P. A. Transmission of Leishmania metacyclic promastigotes by phlebotomine sand flies. Int. J. Parasitol., 2007, 37, 1097-106.

[3] Rogers, M. E.; Ilg, T.; Nikolaev, A. V.; Ferguson, M. A.; Bates, P. A. Transmission of cutaneous leishmaniasis by sand flies is enhanced by regurgitation of fPPG. Nature., 2004, 430, 463-7.

[4] Burchmore, R. J.; Barrett, M. P. Life in vacuoles--nutrient acquisition by Leishmania amastigotes. Int. J. Parasitol., 2001, 31, 131120

[5] Handman, E.; Bullen, D. V. Interaction of Leishmania with the host macrophage. Trends Parasitol., 2002, 18, 332-4.

[6] Feasey, N.; Wansbrough-Jones, M.; Mabey, D. C.; Solomon, A. W. Neglected tropical diseases. Br. Med. Bull., 2010, 93, 179-200.

[7] Alvar, J.; Yactayo, S.; Bern, C. Leishmaniasis and poverty. Trends Parasitol., 2006, 22, 552-7.

[8] Chappuis, F.; Sundar, S.; Hailu, A.; Ghalib, H.; Rijal, S.; Peeling, R. W.; Alvar, J.; Boelaert, M. Visceral leishmaniasis: what are the needs for diagnosis, treatment and control? Nat. Rev. Microbiol., 2007, 5, 873-82.

[9] Croft, S. L.; Sundar, S.; Fairlamb, A. H. Drug resistance in leishmaniasis. Clin. Microbiol. Rev., 2006, 19, 111-26.

[10] Sundar, S.; More, D. K.; Singh, M. K.; Singh, V. P.; Sharma, S.; Makharia, A.; Kumar, P. C.; Murray, H. W. Failure of pentavalent antimony in visceral leishmaniasis in India: report from the center of the Indian epidemic. Clin. Infect. Dis., 2000, 31, 1104-7.

[11] Alvar, J.; Croft, S.; Olliaro, P. Chemotherapy in the treatment and control of leishmaniasis. Adv. Parasitol., 2006, 61, 223-74.

[12] Olliaro, P. L.; Guerin, P. J.; Gerstl, S.; Haaskjold, A. A.; Rottingen, J. A.; Sundar, S. Treatment options for visceral leishmaniasis: a systematic review of clinical studies done in India, 1980-2004. Lancet Infect. Dis., 2005, 5, 763-74.

[13] Sundar, S.; Sinha, P. R.; Agrawal, N. K.; Srivastava, R.; Rainey, P. M.; Berman, J. D.; Murray, H. W.; Singh, V. P. A cluster of cases of severe cardiotoxicity among kala-azar patients treated with a high-osmolarity lot of sodium antimony gluconate. Am. J. Trop. Med. Hyg., 1998, 59, 139-43.
[14] Chulay, J. D.; Fleckenstein, L.; Smith, D. H. Pharmacokinetics of antimony during treatment of visceral leishmaniasis with sodium stibogluconate or meglumine antimoniate. Trans. R. Soc. Trop. Med. Hyg., 1988, 82, 69-72.

[15] Valladares, J. E.; Riera, C.; Alberola, J.; Gallego, M.; Portus, M.; Cristofol, C.; Franquelo, C.; Arboix, M. Pharmacokinetics of meglumine antimoniate after administration of a multiple dose in dogs experimentally infected with Leishmania infantum. Vet. Parasitol., 1998, 75, 33-40.

[16] Frezard, F.; Martins, P. S.; Barbosa, M. C.; Pimenta, A. M.; Ferreira, W. A.; de Melo, J. E.; Mangrum, J. B.; Demicheli, C. New insights into the chemical structure and composition of the pentavalent antimonial drugs, meglumine antimonate and sodium stibogluconate. J. Inorg. Biochem., 2008, 102, 656-65.

[17] Berman, J. D.; Waddell, D.; Hanson, B. D. Biochemical mechanisms of the antileishmanial activity of sodium stibogluconate. Antimicrob. Agents. Chemother., 1985, 27, 916-20.

[18] Berman, J. D.; Gallalee, J. V.; Best, J. M. Sodium stibogluconate (Pentostam) inhibition of glucose catabolism via the glycolytic pathway, and fatty acid beta-oxidation in Leishmania mexicana amastigotes. Biochem. Pharmacol., 1987, 36, 197-201.

[19] Wyllie, S.; Cunningham, M. L.; Fairlamb, A. H. Dual action of antimonial drugs on thiol redox metabolism in the human pathogen Leishmania donovani. J. Biol. Chem., 2004, 279, 39925-32.

[20] Meyerhoff, A. U.S. Food and Drug Administration approval of AmBisome (liposomal amphotericin B) for treatment of visceral leishmaniasis. Clin. Infect. Dis., 1999, 28, 42-8; discussion 49-51.

[21] Sundar, S.; Mehta, H.; Suresh, A. V.; Singh, S. P.; Rai, M.; Murray, H. W. Amphotericin B treatment for Indian visceral leishmaniasis: conventional versus lipid formulations. Clin. Infect. Dis., 2004, 38, 377-83.

[22] Sundar, S.; Agrawal, G.; Rai, M.; Makharia, M. K.; Murray, H. W. Treatment of Indian visceral leishmaniasis with single or daily infusions of low dose liposomal amphotericin B: randomised trial. BMJ., 2001, 323, 419-22.

[23] Sundar, S.; Jha, T. K.; Thakur, C. P.; Mishra, M.; Singh, V. P.; Buffels, R. Single-dose liposomal amphotericin B in the treatment of visceral leishmaniasis in India: a multicenter study. Clin. Infect. Dis., 2003, 37, 800-4.

[24] Sundar, S.; Chakravarty, J.; Agarwal, D.; Rai, M.; Murray, H. W. Single-dose liposomal amphotericin B for visceral leishmaniasis in India. N. Engl. J. Med., 2010, 362, 504-12.

[25] Sundar, S.; Mehta, H.; Chhabra, A.; Singh, V.; Chauhan, V.; Desjeux, P.; Rai, M. Amphotericin B colloidal dispersion for the treatment of Indian visceral leishmaniasis. Clin. Infect. Dis., 2006, 42, 608-13.

[26] Sundar, S.; Singh, A.; Agarwal, D.; Rai, M.; Agrawal, N.; Chakravarty, J. Safety and efficacy of high-dose infusions of a preformed amphotericin B fat emulsion for treatment of Indian visceral leishmaniasis. Am. J. Trop. Med. Hyg., 2009, 80, 700-3.

[27] Sundar, S.; Chakravarty, J.; Agarwal, D.; Shah, A.; Agrawal, N.; Rai, M. Safety of a pre-formulated amphotericin B lipid emulsion for the treatment of Indian Kala-azar. Trop. Med. Int. Health., 2008, 13, 1208-12.

[28] Olliaro, P.; Darley, S.; Laxminarayan, R.; Sundar, S. Costeffectiveness projections of single and combination therapies for visceral leishmaniasis in Bihar, India. Trop. Med. Int. Health., 2009, 14, 918-25.

[29] Bern, C.; Adler-Moore, J.; Berenguer, J.; Boelaert, M.; den Boer, M.; Davidson, R. N.; Figueras, C.; Gradoni, L.; Kafetzis, D. A.; Ritmeijer, K.; Rosenthal, E.; Royce, C.; Russo, R.; Sundar, S.; Alvar, J. Liposomal amphotericin B for the treatment of visceral leishmaniasis. Clin. Infect. Dis., 2006, 43, 917-24.

[30] Adler-Moore, J.; Proffitt, R. T. AmBisome: liposomal formulation, structure, mechanism of action and pre-clinical experience. $J$. Antimicrob. Chemother., 2002, 49 (Suppl 1), 21-30.

[31] WHO, Report of a WHO informal consultation on liposomal amphotericin $\mathrm{B}$ in the treatment of visceral leishmaniasis. WHO/CDS/NTD/IDM/2007.4 2007.

[32] Gradoni, L.; Davidson, R. N.; Orsini, S.; Betto, P.; Giambenedetti, M. Activity of liposomal amphotericin B (AmBisome) against Leishmania infantum and tissue distribution in mice. J. Drug Target., 1993, 1, 311-6.

[33] Pourshafie, M.; Morand, S.; Virion, A.; Rakotomanga, M.; Dupuy, C.; Loiseau, P. M. Cloning of S-adenosyl-L-methionine:C-24 
Delta-sterol-methyltransferase (ERG6) from Leishmania donovani and characterization of mRNAs in wild-type and amphotericin BResistant promastigotes. Antimicrob. Agents Chemother., 2004, 48, 2409-14.

[34] Brajtburg, J.; Bolard, J. Carrier effects on biological activity of amphotericin B. Clin. Microbiol. Rev., 1996, 9, 512-31.

[35] Sindermann, H.; Engel, J. Development of miltefosine as an oral treatment for leishmaniasis. Trans. R. Soc. Trop. Med. Hyg., 2006, 100 Suppl 1, S17-20.

[36] Bhattacharya, S. K.; Sinha, P. K.; Sundar, S.; Thakur, C. P.; Jha, T. K.; Pandey, K.; Das, V. R.; Kumar, N.; Lal, C.; Verma, N.; Singh, V. P.; Ranjan, A.; Verma, R. B.; Anders, G.; Sindermann, H.; Ganguly, N. K. Phase 4 trial of miltefosine for the treatment of Indian visceral leishmaniasis. J. Infect. Dis., 2007, 196, 591-8.

[37] Dorlo, T. P.; van Thiel, P. P.; Huitema, A. D.; Keizer, R. J.; de Vries, H. J.; Beijnen, J. H.; de Vries, P. J. Pharmacokinetics of miltefosine in Old World cutaneous leishmaniasis patients. Antimicrob. Agents. Chemother., 2008, 52, 2855-60.

[38] Bryceson, A. A policy for leishmaniasis with respect to the prevention and control of drug resistance. Trop. Med. Int. Health., 2001, 6, 928-34.

[39] Seifert, K.; Matu, S.; Javier Perez-Victoria, F.; Castanys, S.; Gamarro, F.; Croft, S. L. Characterisation of Leishmania donovani promastigotes resistant to hexadecylphosphocholine (miltefosine). Int. J. Antimicrob. Agents., 2003, 22, 380-7.

[40] Seifert, K.; Perez-Victoria, F. J.; Stettler, M.; Sanchez-Canete, M. P.; Castanys, S.; Gamarro, F.; Croft, S. L. Inactivation of the miltefosine transporter, LdMT, causes miltefosine resistance that is conferred to the amastigote stage of Leishmania donovani and persists in vivo. Int. J. Antimicrob. Agents, 2007, 30, 229-35.

[41] Perez-Victoria, F. J.; Gamarro, F.; Ouellette, M.; Castanys, S. Functional cloning of the miltefosine transporter. A novel P-type phospholipid translocase from Leishmania involved in drug resistance. J. Biol. Chem., 2003, 278, 49965-71.

[42] Perez-Victoria, F. J.; Sanchez-Canete, M. P.; Castanys, S.; Gamarro, F. Phospholipid translocation and miltefosine potency require both L. donovani miltefosine transporter and the new protein LdRos3 in Leishmania parasites. J. Biol. Chem., 2006, 281, 2376675.

[43] Perez-Victoria, F. J.; Sanchez-Canete, M. P.; Seifert, K.; Croft, S. L.; Sundar, S.; Castanys, S.; Gamarro, F. Mechanisms of experimental resistance of Leishmania to miltefosine: Implications for clinical use. Drug. Resist. Updat., 2006, 9, 26-39.

[44] Lux, H.; Hart, D. T.; Parker, P. J.; Klenner, T. Ether lipid metabolism, GPI anchor biosynthesis, and signal transduction are putative targets for anti-leishmanial alkyl phospholipid analogues. Adv. Exp. Med. Biol., 1996, 416, 201-211.

[45] Lux, H.; Heise, N.; Klenner, T.; Hart, D.; Opperdoes, F. R. Ether-lipid (alkyl-phospholipid) metabolism and the mechanism of action of ether--lipid analogues in Leishmania. Mol. Biochem. Parasitol., 2000, 111, 1-14.

[46] Luque-Ortega, J. R.; Rivas, L. Miltefosine (hexadecylphosphocholine) inhibits cytochrome c oxidase in Leishmania donovani promastigotes. Antimicrob. Agents Chemother., 2007, 51, 1327-32.

[47] Rakotomanga, M.; Blanc, S.; Gaudin, K.; Chaminade, P.; Loiseau, P. M. Miltefosine affects lipid metabolism in Leishmania donovani promastigotes. Antimicrob. Agents Chemother., 2007, 51, 1425-30.

[48] Sundar, S.; Jha, T. K.; Thakur, C. P.; Sinha, P. K.; Bhattacharya, S. $\mathrm{K}$. Injectable paromomycin for Visceral leishmaniasis in India. $N$. Engl. J. Med., 2007, 356, 2571-81.

[49] Sundar, S.; Agrawal, N.; Arora, R.; Agarwal, D.; Rai, M.; Chakravarty, J. Short-course paromomycin treatment of visceral leishmaniasis in India: 14-day vs 21-day treatment. Clin. Infect. Dis., 2009, 49, 914-8.

[50] Davidson, R. N.; den Boer, M.; Ritmeijer, K. Paromomycin. Trans. R. Soc. Trop. Med. Hyg., 2009, 103, 653-60.

[51] Ben Salah, A.; Buffet, P. A.; Morizot, G.; Ben Massoud, N.; Zaatour, A.; Ben Alaya, N.; Haj Hamida, N. B.; El Ahmadi, Z.; Downs, M. T.; Smith, P. L.; Dellagi, K.; Grogl, M. WR279,396, a third generation aminoglycoside ointment for the treatment of Leishmania major cutaneous leishmaniasis: a phase 2, randomized, double blind, placebo controlled study. PLoS Negl. Trop. Dis., 2009, 3, e432.

[52] Garnier, T.; Croft, S. L. Topical treatment for cutaneous leishmaniasis. Curr. Opin. Investig. Drugs, 2002, 3, 538-44.
[53] Kanyok, T. P.; Killian, A. D.; Rodvold, K. A.; Danziger, L. H. Pharmacokinetics of intramuscularly administered aminosidine in healthy subjects. Antimicrob. Agents. Chemother., 1997, 41, 982-6.

[54] Maarouf, M.; Lawrence, F.; Croft, S. L.; Robert-Gero, M. Ribosomes of Leishmania are a target for the aminoglycosides. Parasitol. Res., 1995, 81, 421-5.

[55] Maarouf, M.; de Kouchkovsky, Y.; Brown, S.; Petit, P. X.; RobertGero, M. In vivo interference of paromomycin with mitochondrial activity of Leishmania. Exp. Cell. Res., 1997, 232, 339-48.

[56] Maarouf, M.; Lawrence, F.; Brown, S.; Robert-Gero, M. Biochemical alterations in paromomycin-treated Leishmania donovani promastigotes. Parasitol. Res., 1997, 83, 198-202.

[57] Maarouf, M.; Adeline, M. T.; Solignac, M.; Vautrin, D.; RobertGero, M. Development and characterization of paromomycinresistant Leishmania donovani promastigotes. Parasite., 1998, 5, 167-73.

[58] Jhingran, A.; Chawla, B.; Saxena, S.; Barrett, M. P.; Madhubala, R. Paromomycin: uptake and resistance in Leishmania donovani. Mol. Biochem. Parasitol., 2009, 164, 111-7.

[59] Langreth, S. G.; Berman, J. D.; Riordan, G. P.; Lee, L. S. Finestructural alterations in Leishmania tropica within human macrophages exposed to antileishmanial drugs in vitro. J. Protozool., 1983, 30, 555-61.

[60] Croft, S. L.; Brazil, R. P. Effect of pentamidine isethionate on the ultrastructure and morphology of Leishmania mexicana amazonensis in vitro. Ann. Trop. Med. Parasitol., 1982, 76, 37-43.

[61] Vercesi, A. E.; Docampo, R. Ca2+ transport by digitoninpermeabilized Leishmania donovani. Effects of $\mathrm{Ca} 2+$, pentamidine and WR-6026 on mitochondrial membrane potential in situ. Biochem. J., 1992, 284, 463-7.

[62] Vercesi, A. E.; Rodrigues, C. O.; Catisti, R.; Docampo, R. Presence of a $\mathrm{Na}(+) / \mathrm{H}(+)$ exchanger in acidocalcisomes of Leishmania donovani and their alkalization by anti-leishmanial drugs. FEBS Lett., 2000, 473, 203-6.

[63] Mukherjee, A.; Padmanabhan, P. K.; Sahani, M. H.; Barrett, M. P.; Madhubala, R. Roles for mitochondria in pentamidine susceptibility and resistance in Leishmania donovani. Mol. Biochem. Parasitol., 2006, 145, 1-10.

[64] Basselin, M.; Denise, H.; Coombs, G. H.; Barrett, M. P. Resistance to pentamidine in Leishmania mexicana involves exclusion of the drug from the mitochondrion. Antimicrob. Agents. Chemother. 2002, 46, 3731-8.

[65] Yeates, C. Sitamaquine (GlaxoSmithKline/Walter Reed Army Institute). Curr. Opin. Investig. Drugs., 2002, 3, 1446-52.

[66] Tekwani, B. L.; Walker, L. A. 8-Aminoquinolines: future role as antiprotozoal drugs. Curr. Opin. Infect. Dis., 2006, 19, 623-31.

[67] Wasunna, M. K.; Rashid, J. R.; Mbui, J.; Kirigi, G.; Kinoti, D.; Lodenyo, H.; Felton, J. M.; Sabin, A. J.; Albert, M. J.; Horton, J. A phase II dose-increasing study of sitamaquine for the treatment of visceral leishmaniasis in Kenya. Am. J. Trop. Med. Hyg., 2005, 73, 871-6.

[68] Jha, T. K.; Sundar, S.; Thakur, C. P.; Felton, J. M.; Sabin, A. J.; Horton, J. A phase II dose-ranging study of sitamaquine for the treatment of visceral leishmaniasis in India. Am. J. Trop. Med. Hyg., 2005, 73, 1005-11.

[69] Theoharides, A. D.; Chung, H.; Velazquez, H. Metabolism of a potential 8-aminoquinoline antileishmanial drug in rat liver microsomes. Biochem. Pharmacol., 1985, 34, 181-8.

[70] Idowu, O. R.; Peggins, J. O.; Brewer, T. G. Side-chain hydroxylation in the metabolism of 8 -aminoquinoline antiparasitic agents. Drug. Metab. Dispos., 1995, 23, 18-27.

[71] Taylor, T.; Hawkins, D. R.; Morris, G. R.; Chung, H. Pharmacokinetics of the anti-leishmanian agent WR 6026 in dogs. Eur. J. Drug. Metab. Pharmacokinet., 1991, Spec No 3, 136-9.

[72] Lopez-Martin, C.; Perez-Victoria, J. M.; Carvalho, L.; Castanys, S.; Gamarro, F. Sitamaquine sensitivity in Leishmania species is not mediated by drug accumulation in acidocalcisomes. Antimicrob. Agents Chemother., 2008, 52, 4030-6.

[73] Duenas-Romero, A. M.; Loiseau, P. M.; Saint-Pierre-Chazalet, M. Interaction of sitamaquine with membrane lipids of Leishmania donovani promastigotes. Biochim. Biophys. Acta., 2007, 1768, 24652.

[74] Croft, S. L.; Seifert, K.; Yardley, V. Current scenario of drug development for leishmaniasis. Indian J. Med Res., 2006, 123, 399410. 
[75] Fournet, A.; Barrios, A. A.; Munoz, V.; Hocquemiller, R.; Cave, A.; Bruneton, J. 2-substituted quinoline alkaloids as potential antileishmanial drugs. Antimicrob. Agents. Chemother., 1993, 37, 859-63.

[76] Fournet, A.; Gantier, J. C.; Gautheret, A.; Leysalles, L.; Munos, M. H.; Mayrargue, J.; Moskowitz, H.; Cave, A.; Hocquemiller, R. The activity of 2-substituted quinoline alkaloids in BALB/c mice infected with Leishmania donovani. J. Antimicrob. Chemother., 1994, 33, 537-44.

[77] Fakhfakh, M. A.; Fournet, A.; Prina, E.; Mouscadet, J. F.; Franck, X.; Hocquemiller, R.; Figadere, B. Synthesis and biological evaluation of substituted quinolines: potential treatment of protozoal and retroviral co-infections. Bioorg. Med. Chem., 2003, 11, 5013-23.

[78] Nakayama, H.; Loiseau, P. M.; Bories, C.; Torres de Ortiz, S.; Schinini, A.; Serna, E.; Rojas de Arias, A.; Fakhfakh, M. A.; Franck, X.; Figadere, B.; Hocquemiller, R.; Fournet, A. Efficacy of orally administered 2 -substituted quinolines in experimental murine cutaneous and visceral leishmaniases. Antimicrob. Agents Chemother., 2005, 49, 4950-6.

[79] Desrivot, J.; Edlund, P. O.; Svensson, R.; Baranczewski, P.; Fournet, A.; Figadere, B.; Herrenknecht, C. Metabolism of 2substituted quinolines with antileishmanial activity studied in vitro with liver microsomes, hepatocytes and recombinantly expressed enzymes analyzed by LC/MS. Toxicology, 2007, 235, 27-38.

[80] Desrivot, J.; Herrenknecht, C.; Ponchel, G.; Garbi, N.; Prina, E.; Fournet, A.; Bories, C.; Figadere, B.; Hocquemiller, R.; Loiseau, P. M. Antileishmanial 2-substituted quinolines: in vitro behaviour towards biological components. Biomed. Pharmacother., 2007, 61, 441-50.

[81] Nanayakkara, N. P.; Ager, A. L., Jr.; Bartlett, M. S.; Yardley, V.; Croft, S. L.; Khan, I. A.; McChesney, J. D.; Walker, L. A. Antiparasitic activities and toxicities of individual enantiomers of the 8aminoquinoline 8-[(4-amino-1-methylbutyl)amino]-6-methoxy-4methyl-5-[3,4-dichlorophenoxy ]quinoline succinate. Antimicrob. Agents Chemother., 2008, 52, 2130-7.

[82] Jain, M.; Khan, S. I.; Tekwani, B. L.; Jacob, M. R.; Singh, S.; Singh, P. P.; Jain, R. Synthesis, antimalarial, antileishmanial, and antimicrobial activities of some 8-quinolinamine analogues. Bioorg. Med. Chem., 2005, 13, 4458-66.

[83] Kaur, K.; Patel, S. R.; Patil, P.; Jain, M.; Khan, S. I.; Jacob, M. R.; Ganesan, S.; Tekwani, B. L.; Jain, R. Synthesis, antimalarial, antileishmanial, antimicrobial, cytotoxicity, and methemoglobin (MetHB) formation activities of new 8-quinolinamines. Bioorg. Med. Chem., 2007, 15, 915-30.

[84] Croft, S. L.; Hogg, J.; Gutteridge, W. E.; Hudson, A. T.; Randall, A. W. The activity of hydroxynaphthoquinones against Leishmania donovani. J Antimicrob Chemother., 1992, 30, 827-32.

[85] Mantyla, A.; Garnier, T.; Rautio, J.; Nevalainen, T.; Vepsalainen, J.; Koskinen, A.; Croft, S. L.; Jarvinen, T. Synthesis, in vitro evaluation, and antileishmanial activity of water-soluble prodrugs of buparvaquone. J. Med. Chem., 2004, 47, 188-95.

[86] Mantyla, A.; Rautio, J.; Nevalainen, T.; Vepsalainen, J.; Juvonen, R.; Kendrick, H.; Garnier, T.; Croft, S. L.; Jarvinen, T. Synthesis and antileishmanial activity of novel buparvaquone oxime derivatives. Bioorg. Med. Chem., 2004, 12, 3497-502.

[87] Garnier, T.; Mantyla, A.; Jarvinen, T.; Lawrence, M. J.; Brown, M. B.; Croft, S. L. Topical buparvaquone formulations for the treatment of cutaneous leishmaniasis. J. Pharm. Pharmacol., 2007, 59, 41-9.

[88] Garnier, T.; Mantyla, A.; Jarvinen, T.; Lawrence, J.; Brown, M.; Croft, S. In vivo studies on the antileishmanial activity of buparvaquone and its prodrugs. J. Antimicrob. Chemother., 2007, 60, 80210 .

[89] Manandhar, K. D.; Yadav, T. P.; Prajapati, V. K.; Kumar, S.; Rai, M.; Dube, A.; Srivastava, O. N.; Sundar, S. Antileishmanial activity of nano-amphotericin B deoxycholate. J. Antimicrob. Chemother., 2008, 62, 376-80.

[90] Wasan, K. M.; Wasan, E. K.; Gershkovich, P.; Zhu, X.; Tidwell, R. R.; Werbovetz, K. A.; Clement, J. G.; Thornton, S. J. Highly effective oral amphotericin B formulation against murine visceral leishmaniasis. J. Infect. Dis., 2009, 200, 357-60.

[91] Nicoletti, S.; Seifert, K.; Gilbert, I. H. N-(2hydroxypropyl)methacrylamide-amphotericin B (HPMA-AmB) copolymer conjugates as antileishmanial agents. Int. J. Antimicrob. Agents., 2009, 33, 441-8.
[92] Nicoletti, S.; Seifert, K.; Gilbert, I. H., Water-soluble polymer-drug conjugates for combination chemotherapy against visceral leishmaniasis. Bioorg. Med. Chem., 2010, 18, 2559-65.

[93] Jawahar, M. S. Current trends in chemotherapy of tuberculosis. Indian J. Med. Res., 2004, 120, 398-417.

[94] Ellard, G. A. Rationale of the multidrug regimens recommended by a World Health Organization Study Group on Chemotherapy of Leprosy for Control Programs. Int. J. Lepr. Other Mycobact. Dis., 1984, 52, 395-401.

[95] Walker, S. L.; Lockwood, D. N. Leprosy. Clin. Dermatol., 2007, $25,165-72$.

[96] Kremsner, P. G.; Krishna, S. Antimalarial combinations. Lancet. 2004, 364, 285-94

[97] Sundar, S.; Rai, M.; Chakravarty, J.; Agarwal, D.; Agrawal, N.; Vaillant, M.; Olliaro, P.; Murray, H. W. New Treatment Approach in Indian Visceral Leishmaniasis: Single-Dose Liposomal Amphotericin B Followed by Short-Course Oral Miltefosine. Clin. Infect. Dis., 2008, 47, 1000-6.

[98] Melaku, Y.; Collin, S. M.; Keus, K.; Gatluak, F.; Ritmeijer, K.; Davidson, R. N. Treatment of kala-azar in southern Sudan using a 17-day regimen of sodium stibogluconate combined with paromomycin: a retrospective comparison with 30-day sodium stibogluconate monotherapy. Am. J. Trop. Med. Hyg., 2007, 77, 89-94.

[99] Wiese, M. Leishmania MAP kinases--familiar proteins in an unusual context. Int. J. Parasitol., 2007, 37, 1053-62.

[100] Grant, K. M.; Dunion, M. H.; Yardley, V.; Skaltsounis, A. L.; Marko, D.; Eisenbrand, G.; Croft, S. L.; Meijer, L.; Mottram, J. C. Inhibitors of Leishmania mexicana CRK3 cyclin-dependent kinase: chemical library screen and antileishmanial activity. Antimicrob. Agents Chemother., 2004, 48, 3033-42.

[101] Xingi, E.; Smirlis, D.; Myrianthopoulos, V.; Magiatis, P.; Grant, K. M.; Meijer, L.; Mikros, E.; Skaltsounis, A. L.; Soteriadou, K. 6-Br5methylindirubin-3'oxime (5-Me-6-BIO) targeting the leishmanial glycogen synthase kinase-3 (GSK-3) short form affects cell-cycle progression and induces apoptosis-like death: exploitation of GSK3 for treating leishmaniasis. Int. J. Parasitol., 2009, 39, 1289-303.

[102] Naula, C.; Parsons, M.; Mottram, J. C. Protein kinases as drug targets in trypanosomes and Leishmania. Biochim. Biophys. Acta. 2005, 1754, 151-9.

[103] Dujardin, J. C.; Gonzalez-Pacanowska, D.; Croft, S. L.; Olesen, O. F.; Spath, G. F. Collaborative actions in anti-trypanosomatid chemotherapy with partners from disease endemic areas. Trends Parasitol., 2010, 26, 395-403.

[104] Ambit, A.; Fasel, N.; Coombs, G. H.; Mottram, J. C. An essential role for the Leishmania major metacaspase in cell cycle progression. Cell Death Differ., 2008, 15, 113-22.

[105] Fricker, S. P.; Mosi, R. M.; Cameron, B. R.; Baird, I.; Zhu, Y.; Anastassov, V.; Cox, J.; Doyle, P. S.; Hansell, E.; Lau, G.; Langille, J.; Olsen, M.; Qin, L.; Skerlj, R.; Wong, R. S.; Santucci, Z.; McKerrow, J. H. Metal compounds for the treatment of parasitic diseases. J. Inorg. Biochem., 2008, 102, 1839-45.

[106] Bakunov, S. A.; Bakunova, S. M.; Wenzler, T.; Ghebru, M.; Werbovetz, K. A.; Brun, R.; Tidwell, R. R. Synthesis and antiprotozoal activity of cationic 1,4-diphenyl-1H-1,2,3-triazoles. J. Med. Chem., 2010, 53, 254-72.

[107] Patrick, D. A.; Bakunov, S. A.; Bakunova, S. M.; Kumar, E. V.; Chen, H.; Jones, S. K.; Wenzler, T.; Barzcz, T.; Werbovetz, K. A.; Brun, R.; Tidwell, R. R. Synthesis and antiprotozoal activities of dicationic bis(phenoxymethyl)benzenes, bis(phenoxymethyl)naphthalenes, and bis(benzyloxy)naphthalenes. Eur. J. Med. Chem. 2009, 44, 3543-51.

[108] Wilson, W. D.; Tanious, F. A.; Mathis, A.; Tevis, D.; Hall, J. E.; Boykin, D. W. Antiparasitic compounds that target DNA. Biochimie., 2008, 90, 999-1014.

[109] Lorente, S. O.; Rodrigues, J. C.; Jimenez Jimenez, C.; JoyceMenekse, M.; Rodrigues, C.; Croft, S. L.; Yardley, V.; de LucaFradley, K.; Ruiz-Perez, L. M.; Urbina, J.; de Souza, W.; Gonzalez Pacanowska, D.; Gilbert, I. H. Novel azasterols as potential agents for treatment of leishmaniasis and trypanosomiasis. Antimicrob. Agents Chemother., 2004, 48, 2937-50.

[110] Lorente, S. O.; Jimenez, C. J.; Gros, L.; Yardley, V.; de LucaFradley, K.; Croft, S. L.; J, A. U.; Ruiz-Perez, L. M.; Pacanowska, D. G.; Gilbert, I. H. Preparation of transition-state analogues of sterol 24-methyl transferase as potential anti-parasitics. Bioorg. Med. Chem., 2005, 13, 5435-53. 
[111] Gigante, F.; Kaiser, M.; Brun, R.; Gilbert, I. H. SAR studies on azasterols as potential anti-trypanosomal and anti-leishmanial agents. Bioorg. Med. Chem., 2009, 17, 5950-61.

[112] Cammerer, S. B.; Jimenez, C.; Jones, S.; Gros, L.; Lorente, S. O.; Rodrigues, C.; Rodrigues, J. C.; Caldera, A.; Ruiz Perez, L. M.; da Souza, W.; Kaiser, M.; Brun, R.; Urbina, J. A.; Gonzalez Pacanowska, D.; Gilbert, I. H. Quinuclidine derivatives as potential antiparasitics. Antimicrob. Agents Chemother., 2007, 51, 4049-61.

[113] Frearson, J. A.; Wyatt, P. G.; Gilbert, I. H.; Fairlamb, A. H. Target assessment for antiparasitic drug discovery. Trends Parasitol., 2007, 23, 589-95.

[114] Renslo, A. R.; McKerrow, J. H. Drug discovery and development for neglected parasitic diseases. Nat. Chem. Biol., 2006, 2, 701-10.

[115] Hopkins, A. L.; Witty, M. J.; Nwaka, S. Mission possible. Nature, 2007, 449, 166-9.

[116] Aguero, F.; Al-Lazikani, B.; Aslett, M.; Berriman, M.; Buckner, F. S.; Campbell, R. K.; Carmona, S.; Carruthers, I. M.; Chan, A. W.;
Chen, F.; Crowther, G. J.; Doyle, M. A.; Hertz-Fowler, C.; Hopkins, A. L.; McAllister, G.; Nwaka, S.; Overington, J. P.; Pain, A.; Paolini, G. V.; Pieper, U.; Ralph, S. A.; Riechers, A.; Roos, D. S.; Sali, A.; Shanmugam, D.; Suzuki, T.; Van Voorhis, W. C.; Verlinde, C. L. Genomic-scale prioritization of drug targets: the TDR Targets database. Nat. Rev. Drug Discov., 2008, 7, 900-7.

[117] Nwaka, S.; Hudson, A., Innovative lead discovery strategies for tropical diseases. Nat. Rev. Drug Discov., 2006, 5, 941-55.

[118] Nwaka, S.; Ramirez, B.; Brun, R.; Maes, L.; Douglas, F.; Ridley, R. Advancing drug innovation for neglected diseases-criteria for lead progression. PLoS Negl. Trop. Dis., 2009, 3, e440.

[119] Don, R.; Chatelain, E. Drug Discovery for Neglected Diseaes: View of a public private partnership. In: Antiparasitic and antibacterial drug discovery. From molecular targets to drug candidates., 2009, Edited by Paul Selzer, (Wiley-VCH Verlag GmbH \& Co KGaA, Weinheim), 33-43.

(c) Karin Seifert; Licensee Bentham Open.

This is an open access article licensed under the terms of the Creative Commons Attribution Non-Commercial License (http: //creativecommons.org/licenses/by$\mathrm{nc} / 3.0 /$ ) which permits unrestricted, non-commercial use, distribution and reproduction in any medium, provided the work is properly cited. 